\title{
Fabrication of Nanostructured Medical-Grade Stainless Steel by Mechanical Alloying and Subsequent Liquid-Phase Sintering
}

\author{
ERFAN SALAHINEJAD, MOHAMMAD J. HADIANFARD, MOHAMMAD \\ GHAFFARI, SHIRAZEH BAGHERI MASHHADI, and ALI K. OKYAY
}

\begin{abstract}
This article focuses on the microstructure of medical-grade P558 (ASTM F2581) stainless steel produced by mechanical alloying and liquid-phase sintering. Rietveld X-ray diffraction and transmission electron microscopy reflect that the mechanically alloyed stainless steel powder is a nanocrystal dispersed amorphous matrix composite. Mn-11.5 wt pct Si eutectic alloy as additive improves densification of the synthesized P558 alloy via liquid-phase sintering mechanism. $\mathrm{X}$-ray mapping shows that after sintering at $1323 \mathrm{~K}\left(1050^{\circ} \mathrm{C}\right)$ for 1 hour, a uniform distribution of dissolved $\mathrm{Mn}$ and $\mathrm{Si}$ is achieved. Moreover, the development of a nanostructured, fully austenitic stainless steel after sintering at the same temperature is realized by X-ray diffraction and transmission electron microscopy.
\end{abstract}

DOI: $10.1007 / \mathrm{s} 11661-012-1186-5$

(C) The Minerals, Metals \& Materials Society and ASM International 2012

\section{INTRODUCTION}

To meet the best mechanical and corrosion behaviors of powder metallurgy parts, it is well established that high densities are imperative. To do so, several approaches like applying warm compaction, increasing sintering temperature and time, and using proper additives to activate liquid-phase sintering are considered. In the liquid-phase sintering process, the formation of a liquid phase promotes densification via providing a particle rearrangement, faster diffusion rate, and pore elimination, ${ }^{[1,2]}$ opening up the further commercial development of powder metallurgy parts. Concerning powder metallurgy of stainless steels, because high solidstate sintering temperatures generally more than $1573 \mathrm{~K}$ $\left(1300{ }^{\circ} \mathrm{C}\right)$ are required to obtain a high density, ${ }^{[3,4]}$ their liquid-phase sintering process lowering sintering temperature and time is a promising field from scientific and technological viewpoints. To activate liquid-phase sintering of these alloys, various additives like $\mathrm{Cu}, \mathrm{Sn}, \mathrm{Ni}$, $\mathrm{Pt}, \mathrm{Ag}, \mathrm{Si}, \mathrm{Au}, \mathrm{B}$, and $\mathrm{P}$, as well as their compounds and alloys, have been investigated. ${ }^{[1,2]}$

Austenitic stainless steels, typically AISI $316 \mathrm{~L}$, are conventionally used in medical applications; nevertheless,

ERFAN SALAHINEJAD, Ph.D. Student, MOHAMMAD J. HADIANFARD, Professor, and SHIRAZEH BAGHERI MASHHADI, Researcher, are with the Department of Materials Science and Engineering, School of Engineering, Shiraz University, 7134851154, Shiraz, Iran. Contact e-mail: erfan.salahinejad@ gmail.com MOHAMMAD GHAFFARI, Research Assistant, is with the Department of Electrical and Electronics Engineering, UNAM-National Institute of Materials Science and Nanotechnology, Bilkent University, Ankara 06800, Turkey, and with the School of Electrical and Electronic Engineering, Micro Electronic Division, Nanyang Technological University, Singapore 639798, Singapore. ALI K. OKYAY, Assistant Professor, is with the Department of Electrical and Electronics Engineering, UNAM-National Institute of Materials Science and Nanotechnology, Bilkent University.

Manuscript submitted January 4, 2012.

Article published online May 10, 2012 the harmful effects of nickel ions released from this type of implants have provided a high level of motivation for the further development of nickel-free alloys. ${ }^{[5]}$ In the ASTM standards, two nickel-free, medical-grade stainless steels have been imported: ASTM F2229 (nominated as Biodur 108) and ASTM F2581 (nominated as P558). In the recent years, in vitro and in vivo studies have been conducted on the latter having the nominal composition of $\mathrm{Fe}-17 \mathrm{Cr}-10 \mathrm{Mn}-3 \mathrm{Mo}-0.4 \mathrm{Si}-0.5 \mathrm{~N}-0.2 \mathrm{C}$ from the viewpoints of biocompatibility, osseointegration, and corrosion behaviors. $^{[6-11]}$

It is well established that mechanical alloying (MA) can develop a wide variety of equilibrium and nonequilibrium structures including nanostructured and amorphous powders. ${ }^{[12]}$ In this work, mechanically alloyed P558 stainless steel powder is liquid-phase sintered with a biocompatible sintering aid $(\mathrm{Mn}-11.5 \mathrm{wt}$ pct $\mathrm{Si})$ and then the resultant microstructure is evaluated via $\mathrm{X}$-ray diffraction, scanning electron microscopy, X-ray mapping, and transmission electron microscopy.

\section{EXPERIMENTAL WORK}

P558 (ASTM F2581, Fe-17Cr-10Mn-3Mo-0.4Si$0.5 \mathrm{~N}-0.2 \mathrm{C}$ in wt pet) and $\mathrm{Mn}-11.5 \mathrm{wt}$ pet $\mathrm{Si}$ alloy powders were separately processed by MA of $\mathrm{Fe}, \mathrm{Cr}$, $\mathrm{Mn}, \mathrm{Mo}, \mathrm{Si}$, and $\mathrm{C}$ (Merck, Munchen, Germany) and iron nitride (Alfa Aesar, Ward Hill, MA) powders. Milling was performed in a planetary ball mill with a ball-to-powder weight ratio of 20:1 at a rotation speed of $500 \mathrm{rpm}$ for 48 hours under an argon atmosphere. Four bearing steel balls of $20 \mathrm{~mm}$ and 12 bearing steel balls of $8 \mathrm{~mm}$ diameters with a composition of $\mathrm{Fe}-1.5 \mathrm{Cr}-0.9 \mathrm{C}-0.8 \mathrm{Si}-0.5 \mathrm{Mn}$ were used in this work.

The microstructure of the stainless steel powder was studied by X-ray diffraction (XRD; Shimadzu Lab $\mathrm{X}-6000$ with $\mathrm{Cu} \mathrm{K} \alpha$ radiation) with a step size of 0.03 and a step time of 4 seconds. The XRD data were 
analyzed by the Materials Analysis Using Diffraction (MAUD, Version 2.26) program $^{[13]}$ employing the Rietveld refinement to estimate the phase contents and the crystallite sizes by the Double-Voigt approach. In addition, the synthesized powder particles were dispersed in ethanol, dropped down to a copper grid, and characterized by a transmission electron microscope (TEM; FEI-Tecnai G2F30).

The milled stainless steel powder was mixed with 6 wt pct additive powder, milled in acetone for 1 hour, dried at $343 \mathrm{~K}\left(70^{\circ} \mathrm{C}\right)$, encapsulated in evacuated quartz tubes, annealed at $1173 \mathrm{~K}\left(900{ }^{\circ} \mathrm{C}\right)$ for 15 minutes, and finally quenched in water. The obtained powders were pressed using a single acting press at a pressure of $1 \mathrm{GPa}$ without any lubrication. The densification process was followed by sintering at $1273 \mathrm{~K}, 1323 \mathrm{~K}, 1373 \mathrm{~K}, 1423 \mathrm{~K}$, and $1473 \mathrm{~K}$ $\left(1000{ }^{\circ} \mathrm{C}, 1050{ }^{\circ} \mathrm{C}, 1100{ }^{\circ} \mathrm{C}, 1150{ }^{\circ} \mathrm{C}\right.$, and $1200{ }^{\circ} \mathrm{C}$ ) for 1 hour in evacuated quartz tubes and then water-quenched. Sintered densities were determined by the Archimedes water immersion method. The distribution of the additive elements in the structure was analyzed via X-ray mapping (XMAP) by a scanning electron microscope (SEM; FEIQuanta 200 FEG). Moreover, the resultant microstructure after sintering was studied by XRD and TEM. For the TEM sample preparation, a selected sintered specimen was cut into a disc of $3 \mathrm{~mm}$ in diameter, ground to approximately $100 \mu \mathrm{m}$ in thickness, and then electropolished.

\section{RESULTS AND DISCUSSION}

The XRD pattern and TEM micrograph of the as-milled P558 powder are shown in Figure 1. Based on the Rietveld XRD quantitative analysis (the procedure has been detailed in Reference 14), this powder consists of 10 pct ferrite $(\alpha), 48$ pct austenite $(\gamma)$, and 42 pct amorphous phase, where the crystallite size of the ferrite and austenite phases is 11.5 and $12 \mathrm{~nm}$, respectively, measured by the Double-Voigt approach. Note that the relatively low signal-to-noise ratio in the XRD pattern is a result of the presence of the amorphous phase in the material. The selected area diffraction pattern of the TEM micrograph in Figure 1(b) includes some diffraction spots related to the crystalline phases and a halo pattern related to the amorphous phase, confirming that the material has an amorphous/nanocrystalline structure. It is noteworthy that in bright-field TEM images, those crystallites that are close to a zoneaxis orientation appear dark; in contrast, all crystallites that are far off a zone-axis orientation appear bright like the amorphous phase. Additionally, Figure 1(c) presents the high-resolution TEM micrograph of the same powder, in which a consideration to the atomic arrangement depicts a crystalline region embedded in the amorphous matrix, inferring the heterogeneous nucleation of the amorphous phase from grain boundaries of

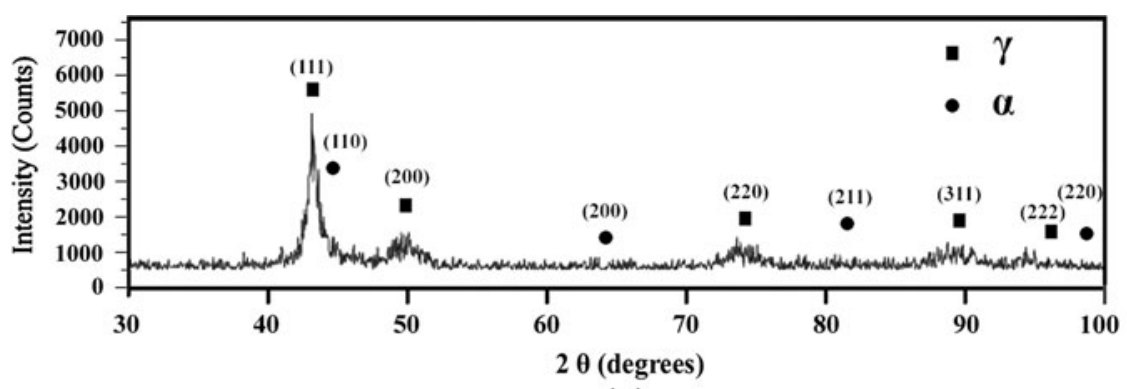

(a)

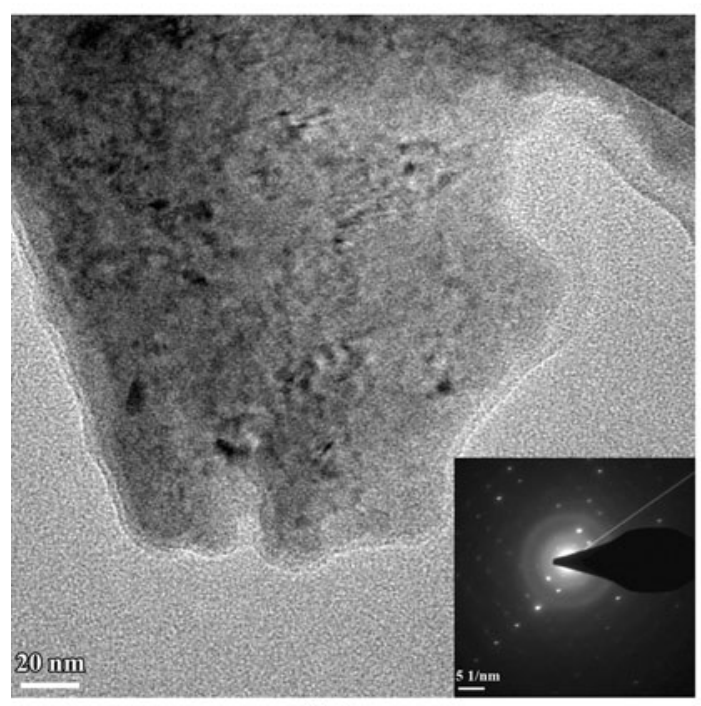

(b)

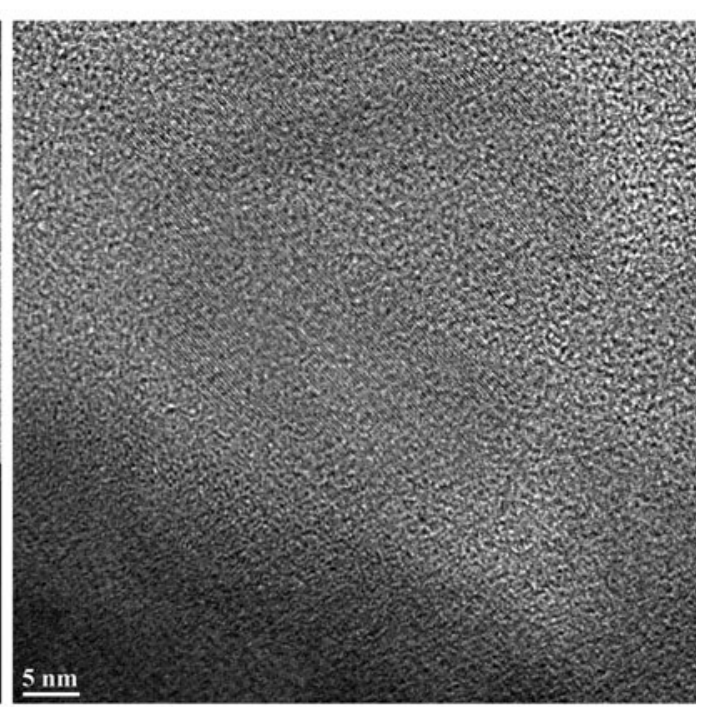

(c)

Fig. 1-XRD pattern (a), TEM micrograph $(b)$, and high-resolution TEM micrograph $(c)$ of the as-milled P558 powder. 
the crystalline phases as high-energy places that are preferential for nucleation. ${ }^{[15,16]}$ The significant structural refinement leading to nanocrystallization can be explained by severe plastic deformation (as a result of the actions of the milling media ${ }^{[12]}$ ) and the contribution of the interstitially dissolved elements $(\mathrm{C}$ and $\mathrm{N})$. Nitrogen ${ }^{[14,17]}$ and carbon ${ }^{[18]}$ atoms are segregated at dislocations and grain boundaries, fixing the dislocations and stabilizing the grain boundaries. Consequently, the trickling down of mobile dislocations on

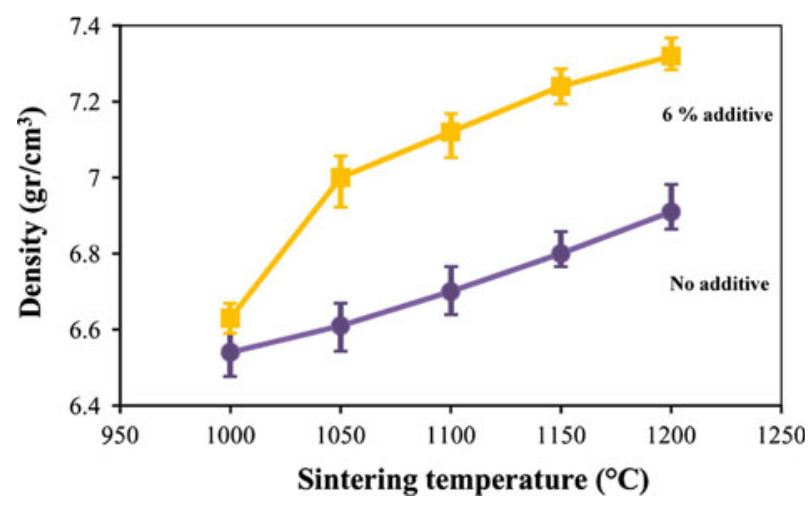

Fig. 2- Sintered densities measured by the Archimedes water immersion method. the fixed dislocations contributes to the nucleation of new boundaries and to a severe grain refinement. A similar contribution to structural refinement has been attributed to the interstitial dissolution of boron in mechanically alloyed Co-based powders. ${ }^{[19]}$ Moreover, amorphization can be explained by severe plastic deformation (accordingly extreme structural refinement), large atomic size mismatch, and negative enthalpy of mixing among the constituent elements. ${ }^{[14,15,17,19]}$

Figure 2 indicates the sintered densities measured by the Archimedes water immersion method. It can be seen that by increasing the sintering temperature and adding the sintering aid, higher densities are achieved. For the samples containing the sintering aid, a sharp increase in density occurs when the sintering temperature increases from $1273 \mathrm{~K}$ to $1323 \mathrm{~K}\left(1000{ }^{\circ} \mathrm{C}\right.$ to $\left.1050{ }^{\circ} \mathrm{C}\right)$, followed by a lower rate densification with the further temperature increase. The additive (Mn-11.5 wt pet $\mathrm{Si}$ ) is a eutectic alloy with a eutectic temperature of $1313 \mathrm{~K}$ $\left(1040{ }^{\circ} \mathrm{C}\right) .{ }^{[20]}$ The formation of the eutectic liquid phase at the temperatures higher than $1313 \mathrm{~K}\left(1040{ }^{\circ} \mathrm{C}\right)$ activates the liquid phase sintering process. Indeed, the formed liquid at the additive particle sites wets the main powder particles, penetrates the particle contacts and pore zones via capillary forces, and provides a path of high diffusivity. With increasing the sintering temperature beyond $1323 \mathrm{~K}\left(1050{ }^{\circ} \mathrm{C}\right)$, the decrease in the

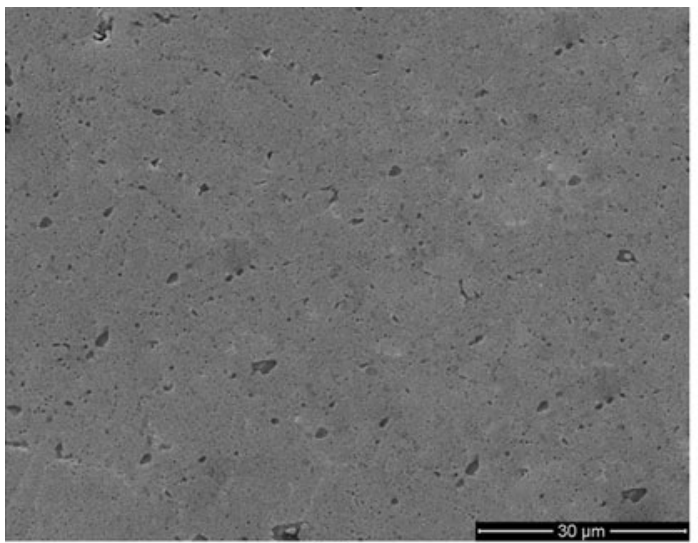

(a)

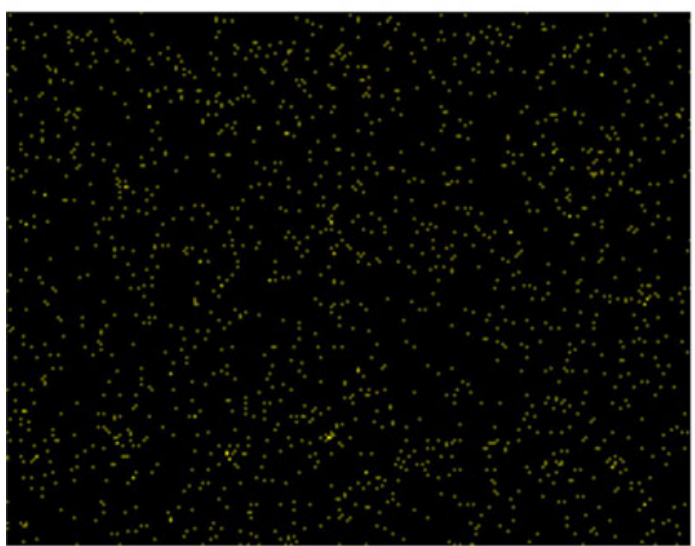

(c)

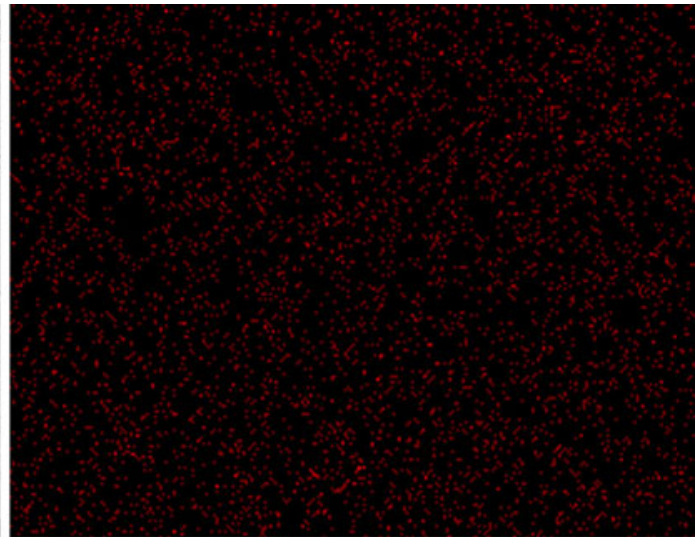

(b)

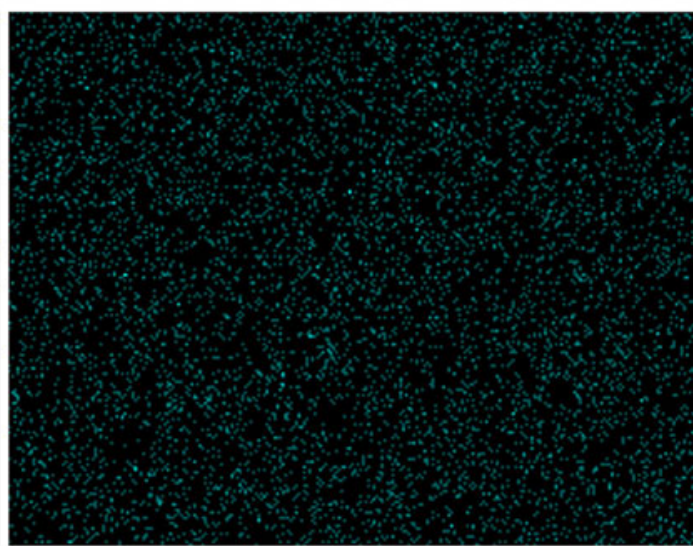

(d)

Fig. 3- SEM micrograph (a) and XMAP of $\mathrm{Mn}(b), \mathrm{Si}(c)$, and $\mathrm{Cr}(d)$ for the additive-containing sample sintered at $1323 \mathrm{~K}\left(1050{ }^{\circ} \mathrm{C}\right)$. 
formed liquid viscosity, the increase in wetting characteristics, the increase in diffusivity, and possibly the increase in the liquid phase amount are responsible for densification. $^{[1,2]}$

Figure 3(a) presents the SEM micrograph of the sample containing 6 pct additive sintered at $1323 \mathrm{~K}\left(1050{ }^{\circ} \mathrm{C}\right)$ for 1 hour. Small, relatively spherical, and isolated pores observed, despite the practiced sintering temperature that is low for solid-state sintering, implies activation of the liquid-phase sintering mechanism. Manganese and Silicon XMAP (Figures 3(b) and (c)) confirms the complete dissolution, no evidence of precipitation, and the uniform distribution of the additive elements in the structure in a scale comparable with the stainless steel particle size (SEM observations of the P558 powder suggested that the particles are almost $20 \mu \mathrm{m}$ in size). In addition, the uniform distribution of $\mathrm{Cr}$ in the structure (Figure 3(d)), which is critical for corrosion protection, infers the merit of processing. The achievement of this uniform microstructure is explained by liquation of the $\mathrm{Mn}-\mathrm{Si}$ eutectic additive and thereby providing a path of high diffusivity. On the other hand, considering the mean size of the main powder particles, which is almost $20 \mu \mathrm{m}$, the mean diffusion length is estimated to be $10 \mu \mathrm{m}$. Indeed, this short diffusion length and the high-diffusivity liquid path justify the development of this homogeneous structure by sintering at $1323 \mathrm{~K}$ $\left(1050{ }^{\circ} \mathrm{C}\right)$ for 60 minutes.

The XRD pattern and TEM micrograph of the additivecontaining sample sintered at $1323 \mathrm{~K}\left(1050^{\circ} \mathrm{C}\right)$ are provided in Figure 4. Analyzing the XRD pattern by MAUD software reflects that the material is fully austenitic based on Rietveld analyses considering all probable phases like nitrides, carbides, and ferrites, demonstrating the competence of the austenitization thermal cycle applied. Albeit, it should be considered that very low phase contents cannot be detected by XRD. According to the TEM micrograph depicted in Figure 4(b), the austenite grain size is almost 25 $\mathrm{nm}$. Considering the atomic arrangement in the highresolution TEM micrograph (Figure 4(c)), the crystallinity of each unit in Figure 4(b) (as a crystalline grain) is confirmed. It is also noticeable that the crystallite size measured by XRD is $35 \mathrm{~nm}$, although it is expected that the XRD crystallite size is smaller than the TEM grain size. It may be because the TEM observation is local, but XRD considers more crystallites. The development of these nanostructures despite the sintering process reflects a considerable thermal stability and an inherent resistance to grain growth, which is in accordance with findings for other multicomponent nanostructures. ${ }^{[21,22]}$ Typically, Cisneros et al. ${ }^{[21]}$ reported austenite grain sizes smaller than $70 \mathrm{~nm}$ for mechanically alloyed $\mathrm{Fe}-18 \mathrm{Cr}-11 \mathrm{Mn}-$ (0.27-2.47) N stainless steel nanostructures after annealing at $1173 \mathrm{~K}, 1273 \mathrm{~K}, 1373 \mathrm{~K}$, and $1473 \mathrm{~K}\left(900{ }^{\circ} \mathrm{C}, 1000{ }^{\circ} \mathrm{C}\right.$, $1100{ }^{\circ} \mathrm{C}$, and $1200^{\circ} \mathrm{C}$ ) for 2 hours. It is known that grain growth is strongly controlled by grain boundary diffusion and mobility. The factors affecting grain boundary mobility in nanostructured materials include grain boundary segregation, solute impurity, porosity, chemical ordering, and second phases. ${ }^{21}$ Indeed, in this study, solute drag effects combined with the typical contribution of carbon and nitrogen are expected to retard grain growth. The solubility of the interstitially dissolved atoms of nitrogen

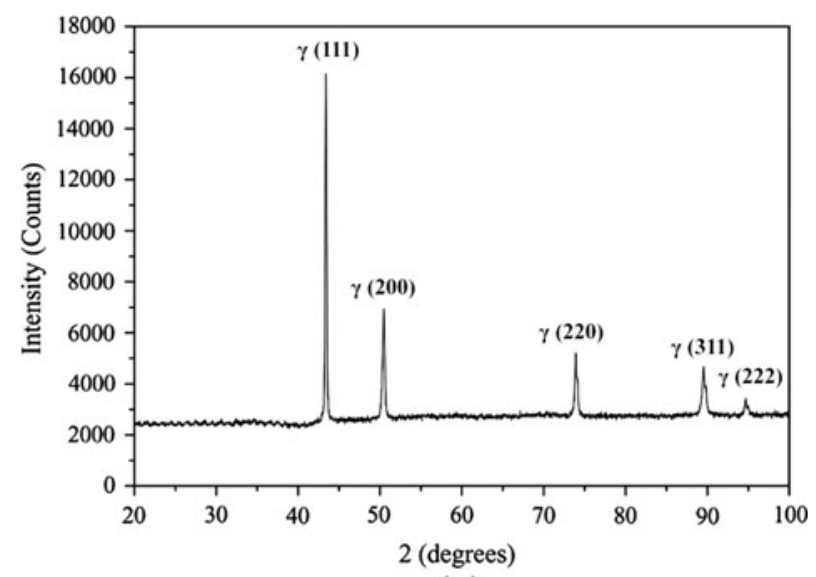

(a)

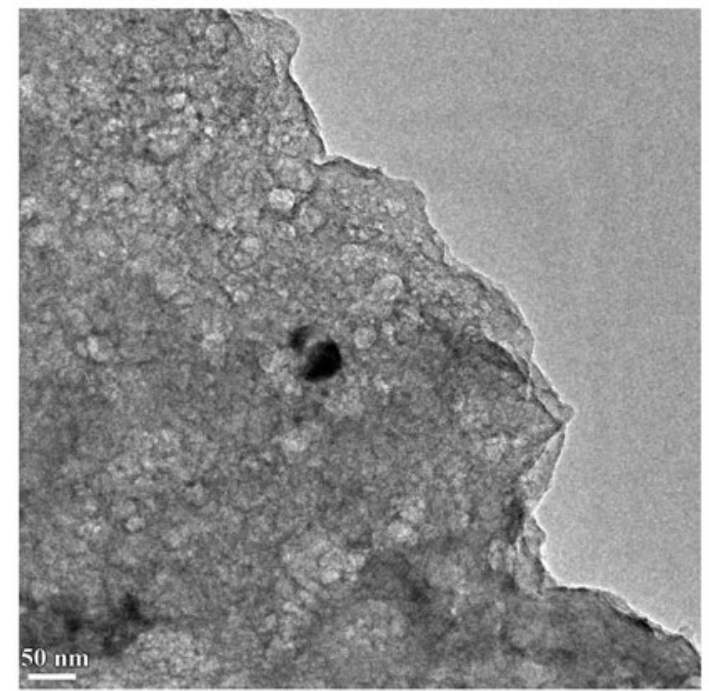

(b)

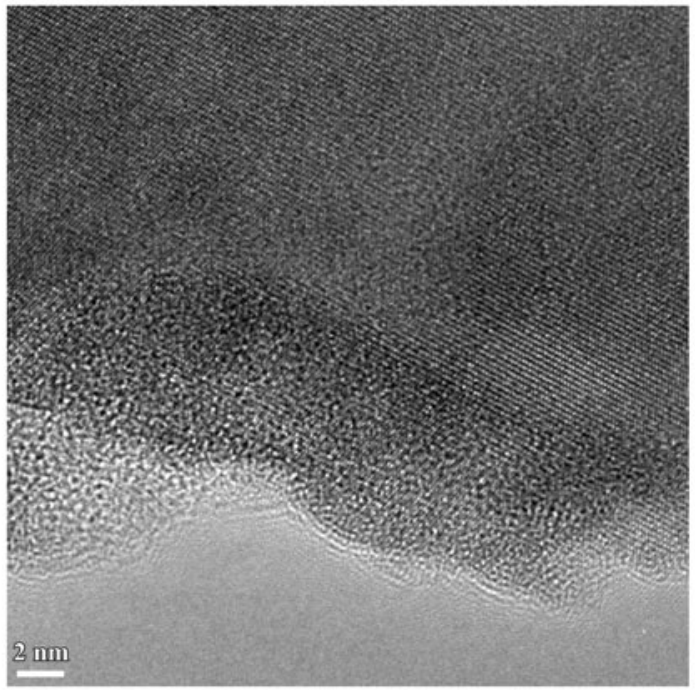

(c)

Fig. 4-XRD pattern (a), TEM micrograph (b), and high-resolution TEM micrograph $(c)$ of the additive-containing sample sintered at $1323 \mathrm{~K}\left(1050^{\circ} \mathrm{C}\right)$.

and carbon in the crystalline phases is limited; thus, they tend to segregate at grain boundaries to decrease strain energy, thereby retarding grain boundary mobility. 
Furthermore, slow crystallization of the amorphous phase developed during MA as a diffusional phase transformation demanding time can affect the final grain size. ${ }^{[23]}$

It is also noteworthy that the final chemical composition of the additive-containing sample would be $\mathrm{Fe}-16 \mathrm{Cr}-14.7 \mathrm{Mn}-2.8 \mathrm{Mo}-1 \mathrm{Si}-0.47 \mathrm{~N}-0.19 \mathrm{C}$. This composition variation as a result of the sintering aid addition, i.e., the increase in the $\mathrm{Mn}$ and $\mathrm{Si}$ content and the decrease in the other elements' amount, could affect mechanical and electrochemical properties. On the other hand, the positive effect of the additive on the increase of density and the decrease of pores should be considered, which demands comprehensive studies on their mechanical and corrosion properties.

\section{CONCLUSIONS}

The microstructure of a medical-grade stainless steel produced by mechanical alloying and subsequent liquidphase sintering processes was investigated. The following results emerge from the present study:

- MA of the stainless steel powder for 48 hours processed a nanocrystal dispersed amorphous matrix composite.

- Mn-Si eutectic alloy as additive successfully activated the liquid-phase sintering mechanism in the P558 alloy powder.

- Uniform distribution of $\mathrm{Mn}, \mathrm{Si}$, and $\mathrm{Cr}$ was realized in the material sintered at $1323 \mathrm{~K}\left(1050{ }^{\circ} \mathrm{C}\right)$.

- Sintering at $1323 \mathrm{~K}\left(1050{ }^{\circ} \mathrm{C}\right)$ for 1 hour developed a fully austenitic nanostructure with grains of $25 \mathrm{~nm}$ in size.

\section{ACKNOWLEDGMENTS}

Parts of this work were supported by EU FP7 Marie Curie IRG Grant 239444, COST NanoTP, TUBITAK EEEAG Grants 108E163 and 109E044 and TUBITAK BIDEB.

\section{REFERENCES}

1. R.M. German: Powder Metallurgy Science, 2nd ed., Metal Powder Industry Federation, 1994, pp. 99-109.

2. E. Klar and P.K. Samal: Powder Metallurgy Stainless Steels: Processing, Microstructures, and Properties, ASM International, Materials Park, OH, 2007, pp. 59-100.

3. J.A.C. Miramontes, J.D.O.B. Sanchez, F.A. Calderon, A.M. Villafane, and J.G.C. Nava: J. Mater. Eng. Perform., 2010, vol. 19, pp. $880-84$.

4. M. Youseffi and K.Y. Chong: Powder Met., 2003, vol. 46, pp. 3038.

5. K. Yang and Y. Ren: Sci. Technol. Adv. Mater., 2010, vol. 11, pp. $1-13$.

6. U.I. Thomann and P.J. Uggowitzer: Wear, 2000, vol. 239, pp. 4858.

7. M. Fini, A.N. Nicoli, P. Torricelli, G. Giavaresi, V. Borsari, H. Lenger, J. Bernauer, R. Giardino, R. Chiesa, and A. Cigada: Biomaterials., 2003, vol. 24, pp. 4929-39.

8. L. Montanaro, M. Cervellati, D. Campoccia, C. Renata Arciola: J. Mater. Sci.: Mater. Med., 2006, vol. 17, pp. 267-75.

9. Y. Ren, H. Yang, K. Yang, and B. Zhang: Key Eng. Mater., 2007, vols. 342-343, pp. 605-08.

10. R.F.V.V. Jaimes, M.L.C.A. Afonso, S.O. Rogero, S.M.L. Agostinho, and C.A. Barbosa: Mater. Lett., 2010, vol. 64, pp. 1476-79.

11. J. Buhagiar, L. Qian, and H. Dong: Surf. Coat. Technol., 2010, vol. 205 , pp. 388-95.

12. C. Suryanarayana: Progr. Mater. Sci., 2001, vol. 46, pp. 1-184.

13. L. Lutterotti: MAUD CPD Newsletter ( $I U C r$ ), 2000, no. 24.

14. R. Amini, M.J. Hadianfard, E. Salahinejad, M. Marasi, and T. Sritharan: J. Mater. Sci., 2009, vol. 44, pp. 136-48.

15. M. Mendez, H. Mancha, M.M. Cisneros, G. Mendoza, J.I. Escalante, and H.F. Lopez: Metall. Mater. Trans. A, 2002, vol. 33A, pp. 3273-78.

16. E. Ma and M. Atzomon: Mater. Chem. Phys., 1995, vol. 39, pp. 249-67.

17. E. Salahinejad, R. Amini, and M.J. Hadianfard: Powder Technol., 2012, vols. 215-216, pp. 247-53.

18. E.P. Yelsukov, G.A. Dorofeev, A.V. Zagainov, N.F. Vildanova, and A.N. Maratkanova: Mater. Sci. Eng. A, 2004, vol. 369, pp. 16-22.

19. A.H. Taghvaei, M. Stoica, G. Vaughan, M. Ghaffari, S. Maleksaeedi, and K. Janghorban: J. Alloys Compd., 2012, vol. 512, pp. 85-93.

20. ASM Handbook: Alloy Phase Diagrams, vol. 3, ASM International, Materials Park, OH, 2003.

21. M.M. Cisneros, H.F. Lopez, H. Mancha, D. Vazquez, E. Valdes, G. Mendoza, and M. Mendez: Metall. Mater. Trans. A, 2002, vol. 33A, pp. 2139-44.

22. K. Lu, Z.F. Dong, I. Bakonyi, and A. Cziraki: Acta Metall. Mater., 1995, vol. 43, pp. 2641-47.

23. R. Amini, E. Salahinejad, E. Askari Bajestani, and M.J. Hadianfard: J. Alloys Compd., 2011, vol. 509, pp. 3252-56. 